\title{
The Effective Taxonomies of Mobile Phone Service Providers' Operations Strategy across Countries: the Case of Arab Middle East Region
}

\author{
Yazan Khalid Abed-Allah Migdadi \\ Business Administration Department, \\ Yarmouk University, Jordan \\ Email: yazan.m@yu.edu.jo
}

\begin{abstract}
The aim of this study is identifying the effective taxonomies of operations strategy of mobile phone service providers across countries. All Arab countries in the Middle East region were surveyed except Syria, and 27 out of 31 service providers were surveyed. Data were collected from corporations' annual reports, websites and other professional institutions published sources. K-means clustering analysis was used to develop clusters and ANOVA test was used to identify the significant differences across clusters in term of relative market share. The adopted taxonomies were; agile, lean oriented, product oriented and cost oriented. Agile, lean oriented and products oriented taxonomies are very close in relative market share and differ significantly from cost oriented. The widely adopted taxonomy across countries is agile.
\end{abstract}

Keywords: taxonomies, operations strategy, mobile phone service providers, middle east

\section{INTRODUCTION}

The studying of taxonomies of operations strategy is a part of operations strategy configurations' research stream which was emerged in the mid 1990s. The research contribution of operations strategy configuration aims to identify the taxonomies or develop the typologies of operations strategies. The taxonomies of operations strategy studies concern about grouping companies based on the actual data. However, typologies research contribution seeks to identify the ideal strategic groups.

The majority of research contribution of operations strategy configuration in general and taxonomies of operations strategy in particular has reported the practices of manufacturing sector (e.g. Miller and Roth, 1994; Kathuria, 2000; Frohlich and Dixon, 2001; Menor et al. 2001; Sum et al. 2004; Zhao et al. 2006; Martin-Pena and Diaz-Garrido 2008). Limited studies have investigated the service sector (e.g. Kellogg and Nie, 1995; Metter and Vargas, 2000; Lowson, 2002; Aranda, 2003; Migdadi, 2013; Migdadi, 2014). The service sector is the dominated sector in the majority of developing and developed countries' economies (Migdadi, 2013). Telecommunication sector is attractive for investigation from social, economic technological and legal perspective (Fuentelsaz et al.,
2008). No any sector connected unconnected areas and achieved significant growth during the last decade the same as telecommunication sector (International Telecommunication Union, 2010).

The growth of telecommunication sector in developed countries is in a saturation stage, however, the growth of telecommunication sector in developing countries is still goes up more significantly than developed countries. The growth of telecommunication sector of the Arab states region is the third ranked after Europe and USA during the period 2009-2010, which reached 75\% (International Telecommunication Union, 2010), and the penetration rate of the Arab states region is the third ranked after CIS and USA (International Telecommunication Union, 2014).

Despite the importance of telecommunication sector, limited studies have investigated the operations strategy of this sector (e.g., Valletti, 1999; Fjeldstad et al., 2004; Dahlstrom et al., 2004; Curwen and Whalley, 2007; Markova et al., 2008; Karabag and Berggren, 2011; Migdadi, 2012). Also very limited studies have investigated this issue in developing countries in general and the Middle East in particular (e.g. Migdadi, 2012).

The majority of previous studies have focused on reporting the taxonomies of operations strategy in a particular country. Reporting taxonomies across countries gives better insight about the effective patterns since the sample is more representative. Accordingly the aim of this study is identifying the effective taxonomies of mobile phone service providers across countries, the Arab countries region in Middle East region was chosen for investigation since it is a leading region in developing in term of growth, penetration rate. This aim was realized through the realization of the following objectives:

1. Identifying the operations competitive capabilities of mobile phone service providers in the Arab Middle East countries.

2. Developing the taxonomies of mobile phone service providers' operations strategy in the Arab Middle East countries.

3. Measuring the effectiveness of taxonomies of operations strategy adopted by mobile phone service providers in the Arab Middle East countries.

4. Identifying the adopted taxonomies by mobile phone service providers in each Arab Middle East country. 
5. Identifying the adopted taxonomies by mobile phone service providers working across Arab Middle East countries.

This paper is issued in five sections; the first section is the literature review, the next section discussed the methodology and methods adopted by this study, then, the data analysis and findings are presented, followed by the discussion section, finally the contribution, results, implications and future research section is presented.

\section{LITERATURE REVIEW}

The configuration of strategy was a research stream by the strategy management researchers, and different configurations were developed as the Miles et al. (1978), Porter (1980), Mintzberg and Water (1985). The configuration as defined by Meyer et al. (1993) is a group of organizations that mirror each other based upon some logical subset of variables. The distinguished characteristic of configuration as concluded by Bozarth and McDermott (1998) is the multi dimensional profiles used to describe organizational, strategy, or process types.

There are two approaches proposed by Miller (1996) to develop strategy configurations; the approach of typology and the approach of taxonomy. The typology and taxonomy have been used interchangeably in much of the relevant literature but they are different (Doty and Glick, 1994).

Doty and Glick (1994) defined typologies are the ideal types each of which represents a unique combination of organizational attributes that are believed to determine the relevant outcomes. While taxonomies defined by Miller (1996) as an empirical classification of mutually exclusive and exhaustive groups by using methods of numerical taxonomy and an assortment of clustering algorithms and hypotheses testing technique to identify the mutual clusters in the data.

Compared to typology approach taxonomy tends to be as discussed by Bozarth and McDermott (1998) more firmly based on facts or at least on quantitative data. Also the classification variables are carefully selected based on existing theory and task on hand. Taxonomies studies test the following question; are the proposed groups stable across techniques and sample data?. However, typology studies provide ground theory and middle range theories which empirically testable. Typology studies test the following question; does greater alignment between an organization and defined ideal types results in a greater organizational performance?

The previous studies have investigated the taxonomies of manufacturing strategy (e.g. Miller and Roth, 1994; Kathuria, 2000; Frohlich and Dixon, 2001; Menor et al. 2001; Sum et al. 2004; Zhao et al. 2006; Martin-Pena and Diaz-Garrido 2008) in one country context (e.g. . Miller and Roth, 1994; Kathuria, 2000; Menor et al. 2001; Sum et al. 2004; Zhao et al. 2006), very limited studies have investigated taxonomies across countries (e.g. Frohlich and Dixon, 2001). These studies have reported the taxonomies only, limited studies have investigated the impact of context on the adopted taxonomies. The contextual factor investigated was the type of industry (e.g. Miller and Roth, 1994; Kathuria, 2000; Menor et al. 2001; Sum et al. 2004;
Zhao et al. 2006). The only study investigated the practices across countries has not investigated the impact of country context (e.g. Frohlich and Dixon, 2001).

To bridge the previous research gaps, this study investigates the taxonomies of operations strategy adopted by the mobile phone service providers in one of the leading regions which is the Middle East. Further, this study investigates the impact of the country context on the adopted taxonomies.

\subsection{The Variables Used to Develop the Taxonomies of Operations Strategy}

Different variables were used in strategy literature to develop the taxonomies of strategies such as the environment or technology, or product life cycle, strategic decisions variables, the scope of their business and the resources. The widely used variable to develop taxonomies of operations strategy is the competitive priorities or capabilities, which was adopted by many researchers of operations strategy such as Miller and Roth (1994), Kathuria (2000), Frohlich and Dixon (2001), Menor et al. (2001) Sum et al. (2004), and Zhao et al. (2006). The competitive capabilities were evaluated from two different perspectives. The first perspective identified the relative importance of each capability of the firm. This perspective was adopted by Miller and Roth (1994), Kathoria (2000), Frohlich and Dixon (2001), and Zhao et al. (2006).

The second perspective decided to identify the actual competitive strength in comparison with major competitors. This perspective was adopted by Menor et al. (2001), and Sum et al. (2004). Which perspective is the most appropriate; according to Zhao et al. (2006) the research objectives will determine this, if the researcher seeks to identify the strategies adopted only, then, the taxonomies will be developed based on the emphasis or the importance places on the competitive capabilities. If the effective taxonomies will be reported, then strength in competitive capabilities might be a more viable alternative to be evaluated (Miller and Roth, 1994)

Other researchers adopted an evolutionary perspective in developing the taxonomies of operations strategy such as the contribution of Lowson $(2002,2003)$. This researcher views the taxonomy of operations strategy as a mapping of the relationship between the building blocks of operations strategy; the core competencies, capabilities and processes, resources, technologies and key tactical activities that are vital to support a particular strategy positioning.

\subsection{The Taxonomies of Operations Strategy}

Different taxonomies of operations strategy have been developed according to the different combinations of operations strategy capabilities of cost quality, delivery, flexibility, broadness of product line and distribution, advertising and after sales service. Miller and Roth (1994) classified the firms to three strategic groups; cartakers, marketers and innovators. Sum et al. (2004) identified three clusters too; all rounder, efficient innovators, and differentiators.

Kothuria (2000) identified four clusters; starters, efficient conformers, speed conformers and do all. Menor et al. (2001) developed four clusters too; agile, traditional, niche and straddlers. Zhao et al. (2006) developed four 
clusters; low emphasize, quality customization, mass server and specialized contractor. Frohlich and Dixon (2001) expanded the list to include six taxonomies; cartakers, marketers, innovators, idlers, servers, and mass customization.

Aranda (2002) developed the service operations taxonomies according to process capabilities, information technology capabilities, work force capabilities, and design capabilities. The capabilities were; push and pull orientation of the service delivery process, back office and front office activities relationship, degree of customer participation, use of information technology, human resource specialization, new service design, the development and number of different service offered, Aranda (2002) developed three clusters of service operations strategy; process oriented, customer oriented, and service oriented.

The number of taxonomies developed is between three to six, the number is affected mainly by the size of sample, the titles provided to each cluster reflects the combination of competitive capabilities of each cluster. Some of the clusters developed by different researchers share the same capabilities but the titles are different. Some taxonomy developed for manufacturing strategies such as Miller and Roth (1994), Kathuria (2000), Frohlich and Dixon (2001), Sum et al. (2004), Zhao et al. (2006), but Menor et al. (2001), Aranda (2002), and Lowson (2002) developed Taxonomies for service sector.

H1: Mobile phone service providers located in the Arab Middle East countries are clustered to different taxonomies of operations strategy.

\subsection{The Performance of Operations Strategies Taxonomies}

Miller and Roth (1994) evaluated the non-financial performance such as manufacturing lead time, changeover set up time, headcount, ratio of blue/white colour employees, outgoing quality, number of grievances, and percentage of new product development.

Sum et al. (2004) evaluated the financial and nonfinancial performance such as overall financial performance, growth in annual sales, growth in market sales, return on sales, return on investment, and growth in investment. Menor et al. (2001) evaluated the non-financial performance indicators such as; business sustainability, quality of customer interface and productivity. The financial performance indicators evaluated were; total assets, return on assets, change on return on assets.

Some researchers found significant differences in performance between groups; such as Miller and Roth (1994), Kathuria (2000), Menor et al. (2001), and Sum et al. (2004), but others such as Zhao et al. (2006) did not find such significant differences.

Miller and Roth (1994) found that the marketers were better than other clusters in changeover set up time, headcount, ratio of blue/white colour employees, but innovators were better in manufacturing lead time, outgoing quality, and percentage of launching new products on time. However, caretaker did not correlate with any performance indicators.
All rounder group of Sum et al. (2004) did not show any significant performance. Efficient innovator showed significant differences in overall financial performance, growth in annual sales and growth in market sales. Differentiator showed significant differences in the growth of market share and return on investment. Menor et al. (2001) found that the agile group was the best in performance among all groups.

Kathuria (2000) found that do all group performed better in customer satisfaction than the starter group, the speedy performers perform better than the starters group on quality of work. Efficient conformers group performs better than other groups in quality of work.

H2: There is a significant difference in performance among the taxonomies of operations strategy adopted by mobile phone service providers in the Arab Middle East region.

\subsection{The Taxonomies Adopted On The Same and Across Countries}

The taxonomies adopted on the same and across countries have investigated by some researchers of operations strategy. The factor investigated was the impact of sectors on the adopted taxonomies (e.g. Miller and Roth, 1994; Lowson et al. 2001; Sum et al. 2004). These studies found that; different taxonomies adopted by different industries, and other studies found that; the organizations of the same industry and country adopted different taxonomies of operations strategy (e.g. Zhao et al. 2006; Menor et al. 2001; Aranda, 2002).

H3: Each mobile phone service provider in each Arab country adopts a unique taxonomy of operations strategy in comparison with other service providers of the same country.

The taxonomies of operations strategy adopted across countries were investigated by limited studies as Frohlich and Dixon (2001). They decided to investigate whether the taxonomies developed by Miller and Roth (1994) in North America are the same for South America, Western Europe and Asia Pacific. The study found that; the Caretaker and innovators were adopted in South America, West Europe and Asia Pacific, and the least adopted around the world were; Idlers, servers, and mass customization.

H4: Mobile phone service providers working across Arab countries in the Middle East are expected to adopt unique operations strategy taxonomy in each country.

\section{METHODOLOGY AND METHODS}

The methodology of this research is a descriptive analytical methodology. Following is the discussion for the methodology adopted.

\subsection{The Sample of Study}

The sample of study includes all mobile phone service providers in the Arab Middle East countries. Table (1) shows the number of service providers in the region. It can be seen that the number of service providers is 31 . The 
sample of this study is a convenient sample according to the data availability. All countries were included in the sample except Syria, and 27 companies were surveyed. The sample included about $87 \%$ of the population. Syria was eliminatedfrom the investigation as a result of unavailability of data.

Table 1 The Consensus of Mobile Phone Service Providers in the Arab Middle East Countries

\begin{tabular}{|l|c|c|c|}
\hline Country & Number of service provides & Sample & \% of corporations surveyed \\
\hline Jordan & 3 & 3 & $100 \%$ \\
\hline Iraq & 3 & 3 & $100 \%$ \\
\hline Lebanon & 3 & 2 & $66 \%$ \\
\hline Syria & 2 & 0 & $0 \%$ \\
\hline Saudi Arabia & 3 & 3 & $100 \%$ \\
\hline Yemen & 3 & 3 & $100 \%$ \\
\hline Oman & 4 & 4 & $100 \%$ \\
\hline United Arab Emirates & 2 & 2 & $100 \%$ \\
\hline Qatar & 2 & 2 & $100 \%$ \\
\hline Bahrain & 3 & 2 & $75 \%$ \\
\hline Kuwait & 3 & 3 & $100 \%$ \\
\hline Number & 31 & 27 & $87 \%$ \\
\hline
\end{tabular}

\subsection{The Operational Definition of Study Variables and The Sources of Data}

3.2.1 The operations competitive capabilities of mobile phones service providers in the Arab Middle East countries

The variables used by this study to develop the taxonomies of operations strategy were the operations competitive capabilities since the aim of this study is to make a comparison between service providers in term of winning criteria, and these criteria are the strengths or the attributes related to services provided to customers. Furthermore, the widely used variables to develop taxonomies of operations strategy were the competitive priorities or capabilities, which were adopted by many researchers of manufacturing strategy such as Miller and Roth (1994), Kathuria (2000), Frohlich and Dixon (2001), Sum et al. (2004), and Zhao et al. (2006), also adopted by a researcher of service operations strategy Menor et al. (2001).
The operations competitive capabilities of mobile service providers are classified to; reduce the prices, improve the service quality (service availability), billing system, range of service provided the offers (Lee et al., 2006; Migdadi, 2012), the accessibility of mobile service (Cairnes and Nikomborirak, 1995; Migdadi; 2012).

The sources of operations competitive capabilities investigated in this study are very close to those recommended by Migdadi (2012). Table (2) shows the sources list of competitive capabilities and the scales, it can be seen that; the operations competitive capabilities were classified to cost of calls service, diversity of basic services, diversity of entertainment services, offers diversity and service accessibility. The data were collected from the service providers' website.

Table 2 The Sources of Competitive Capabilities and the Scales

\begin{tabular}{|l|l|l|}
\hline Source of competitive capabilities & Scale & Sources of data \\
\hline Cost of calls service & Calles rate per minute & Service provider website \\
\hline Diversity of basic services & Number of basic services & Service provider website \\
\hline Diversity of entertainment services & Number of entertainment service & Service provider website \\
\hline Diversity of offers & Number of offers & Service provider website \\
\hline Service accessibility & $\begin{array}{l}\text { Percentage of population areas covered by } \\
\text { service }\end{array}$ & Service provider website \\
\hline
\end{tabular}

3.2.2 The effectiveness of taxonomies of operations strategy adopted by mobile phone service providers in the Middle East region.

The effectiveness of taxonomies of operations strategy is evaluated by using a performance indicator. The performance indicators could be the market share, the customer satisfaction, the customer retention, the customers loyalty, and the financial performance (net income, return on assets, return on equity...etc.). The indicator surveyed in this study is the market share. This indicator was published by all surveyed service providers.

Other indicators as the financial indicator is available for some service providers. The remaining indicators as the customer retention, satisfaction and loyalty are not 
published at all. The market share in this study is defined as the number of served customers by a particular service provider in a particular country in comparison with all service providers in the country. The market share was collected from the annual reports of corporation, or published facts on the corporations' websites or published facts on some professional news sites as Cellular News website (http://www.cellular-new.com) and Middle East Business News website (http://www.ameinfo.com).

\subsection{Data Analysis Techniques}

3.3.1 How to test the first hypothesis, H1: Mobile phone service providers located in the Arab Middle East countries are clustered to different taxonomies of operations strategy.

The taxonomies of operations strategy were developed according to operations competitive capabilities as presented in the followings:

1. A standard relative scale of operations competitive capabilities was developed. The relative index of each service provider's operations competitive capability was developed by comparing the score of each service provider with the best as presented in Table (3) example (1). The relative scale was developed since the aim of this study is to identify the effective taxonomies. According to Miller and Roth (1994) if the effective taxonomy will be reported, then the strength in the competitive capabilities relative to competitors is more viable alternative to be evaluated.

Table 3 Example (1): How to identify the relative operations competitive capability index

\begin{tabular}{|l|l|l|}
\hline Corporation & Number of offers & Relative \\
\hline A & 5 & $(5 / 10) \times 100=50$ \\
\hline B & 10 (best) & $(10 / 10) \times 100=100$ \\
\hline
\end{tabular}

2. The service providers of Middle East region were clustered by using K-means clustering analysis. Different clustering trials were generated in order to identify the best clustering trials. The best trial contains the maximum number of significant operations competitive capabilities.

3. Each cluster represents a strategic group or taxonomy of operations strategy. Each taxonomy was titled according to some adopted titles by the previous studies.

4. The clusters membership list, which is a part of k-means clustering analysis output was used to identify the corporations belong to each cluster.

3.3.2 How to test the second hypothesis, H2: there is a significant difference in performance among the taxonomies of mobile phone service providers' operations strategy in the Arab Middle East region
Analysis of variance (ANOVA) was used for this purpose. Accordingly, F-test, homogeneity test and Scheffe Post hoc test were used for this purpose.

3.3.3 How to test the third, H3: Each mobile phone service provider in each Arab country adopts a unique taxonomy of operations strategy in comparison with other service providers of the same country.

The cluster membership of each taxonomy was identified. The country and service providers related to each taxonomy was identified. Accordingly it is very easy to make a comparison and identify in how many countries the hypothesis is accepted, if it is accepted in more than the half of counties the hypothesis is accepted.

3.3.4 How to test the fourth, H4: Mobile phone service providers working across Arab countries in the Middle East are expected to adopt unique operations strategy taxonomy in each country.

The cluster membership of each taxonomy was identified. Then the service providers working across countries were marked by a shape as circle or triangulation. Then, the taxonomy adopted in each country was identified to test the hypothesis. If the service provider adopted more than one different taxonomy then the hypothesis is accepted for this service provider. If all service providers working across countries adopted more than one taxonomy the hypothesis will be accepted.

\section{DATA ANALYSIS AND FINDINGS}

\subsection{The Taxonomies of Mobile Phone Service Providers' Operations Strategy in the Arab Middle East Region}

Table 4 shows the taxonomies of mobile phone service providers' operations strategy as generated by $\mathrm{K}$ means clustering analysis. It can be seen that; the taxonomies adopted were four. The first taxonomy is called agile, since the corporations of this cluster highly adopted all operations competitive capabilities. The second taxonomy is called lean since the corporations of this cluster highly adopted calls rate per minute and number of basic services. The third taxonomy is called productoriented, since the corporations of this cluster highly adopted the number of offers, number of basic services and number of entertainment services. The fourth taxonomy is called cost-oriented, since the corporations of this cluster highly adopted calls rate per minute.

The widely adopted strategic group is agile which was adopted by ten service providers. The second adopted strategic group was lean. However, the product-oriented and cost-oriented were adopted by five corporations. According to previous results the first hypothesis (H1) is accepted. 
Migdadi: The Effective Taxonomies of Mobile Phone Service Providers' Operations Strategy across Countries 30 Operations and Supply Chain Management 10(1) pp. 25 - 34 (c) 2017

Table 4 The Taxonomies of Mobile Phone Service Providers' Operations Strategy Generated by K-means Clustering Analysis

\begin{tabular}{|c|c|c|c|c|c|}
\hline $\begin{array}{l}\text { Operations } \\
\text { competitive } \\
\text { capabilities }\end{array}$ & $\begin{array}{l}\begin{array}{l}\text { Agile strategic } \\
\text { group }\end{array} \\
\mathrm{N}=10\end{array}$ & $\begin{array}{l}\text { Lean strategic group } \\
\mathrm{N}=7\end{array}$ & $\begin{array}{l}\text { Product oriented } \\
\text { strategic group } \\
\mathrm{N}=5\end{array}$ & $\begin{array}{l}\begin{array}{l}\text { Cost oriented } \\
\text { strategic group }\end{array} \\
\mathrm{N}=5\end{array}$ & ANOVA \\
\hline Calls rate per minute & $\begin{array}{l}79.9^{(\mathbf{a})} \\
(2)^{(\mathbf{b})} \\
H^{(\mathbf{c})}\end{array}$ & $\begin{array}{l}81.29 \\
(1) \\
H\end{array}$ & $\begin{array}{l}54.60 \\
(4) \\
M\end{array}$ & $\begin{array}{l}72 \\
(3) \\
H\end{array}$ & $\begin{array}{l}F=1.523 \\
P=0.235\end{array}$ \\
\hline Number of offers & $\begin{array}{l}76.6 \\
(2) \\
\mathrm{H}\end{array}$ & $\begin{array}{l}52.86 \\
(3) \\
M\end{array}$ & $\begin{array}{l}94.80^{*} \\
(1) \\
\mathrm{H}\end{array}$ & $\begin{array}{l}39 \\
(4) \\
M\end{array}$ & $\begin{array}{l}F=6.603 \\
P=0.002\end{array}$ \\
\hline $\begin{array}{l}\text { Number of basic } \\
\text { services }\end{array}$ & $\begin{array}{l}80.20 \\
\text { (3) } \\
\mathrm{H}\end{array}$ & $\begin{array}{l}91^{*} \\
(1) \\
H\end{array}$ & $\begin{array}{l}84 \\
(2) \\
\mathrm{H}\end{array}$ & $\begin{array}{l}38 \\
(4) \\
M\end{array}$ & $\begin{array}{l}F=4.782 \\
P=0.010\end{array}$ \\
\hline $\begin{array}{l}\text { Number of } \\
\text { entertainment services }\end{array}$ & $\begin{array}{l}97.10^{*} \\
(1) \\
H\end{array}$ & $\begin{array}{l}31.29 \\
\text { (3) } \\
M\end{array}$ & $\begin{array}{l}87 \\
(2) \\
H\end{array}$ & $\begin{array}{l}12 \\
(4) \\
L\end{array}$ & $\begin{array}{l}F=59.059 \\
P=0.000\end{array}$ \\
\hline Service accessibility & $\begin{array}{l}87.60 \\
(2) \\
H\end{array}$ & $\begin{array}{l}90.86^{*} \\
(1) \\
H\end{array}$ & $\begin{array}{l}24.20 \\
\text { (4) } \\
\mathrm{L}\end{array}$ & $\begin{array}{l}26.40 \\
(3) \\
L\end{array}$ & $\begin{array}{l}F=24.982 \\
P=0.000\end{array}$ \\
\hline
\end{tabular}

(a) the cluster average competitive position indicator

(b) the rank of capability index across clusters

(c) the scale of competitive position index $(0-<0.3: \mathrm{L},>0.3-<0.7: \mathrm{M}, 0.7-1.00: \mathrm{H})$

\subsection{The Effectiveness of Taxonomies of Mobile} Phone Service Providers' Operations

\section{Strategy in the Arab Middle East Region}

Table 5 shows that, there is a significant difference between strategic groups in term of relative marker share, the F-value is 10.594 which is significant at p-value less than 0.01. Table (7) shows the result of Scheffe Post hoc test for the differences between strategic groups. It can be seen that; the level of relative market share which realizes by Agile, lean and product-oriented strategic is high, it was $74.2 \%, 89 \%$, and $92.4 \%$ respectively. The relative market share of the cost-oriented strategic group is low, it was $25.6 \%$. The relative market share of agile, lean, and product-oriented is very close, these groups are significantly better than cost-oriented in relative market share. According to previous result the second hypothesis (H2) is accepted.

Table 5 The differences between strategic groups in term of Relative market share (the result of One way ANOVA)

\begin{tabular}{|l|l|l|l|l|l|}
\hline & Sum of squares & $\begin{array}{l}\text { Degree of } \\
\text { freedom }\end{array}$ & Mean square & F-value & p-value \\
\hline Between groups & 14912.519 & 3 & 4970.840 & $10.594^{* *}$ & 0.000 \\
\hline Within group & 10792 & 23 & 469.217 & & \\
\hline Total & 25704.519 & 26 & & & \\
\hline$*$ * & & & & & \\
\hline
\end{tabular}

Table 6 Test of homogeneity of variance

\begin{tabular}{|c|c|c|c|}
\hline Levene Statistics & Df1 & Df2 & Sig \\
\hline 2.061 & 3 & 23 & 0.133 \\
\hline
\end{tabular}




\subsection{The Taxonomies of Mobile Phone Service Providers' Operations Strategy Adopted by Corporation of Each Country}

Table 8 shows the clusters membership for taxonomies of operations strategy adopted by each corporation in each Arab Middle East country. It can be seen that; the mobile phone service providers in six countries (UAE, Qatar, Lebanon, KSA, Bahrain, and Iraq) adopted different taxonomy in companion with competitors in the same country. However, this result was partially supported by the mobile phone service providers in five countries (Oman, Yemen, Kuwait, and Jordan). So generally speaking the third hypothesis (H3) is accepted.

\subsection{The Taxonomies of Mobile Phone Service Providers' Operations Strategy Adopted by Corporation Working Across Arab Middle East Countries}

Table 8 shows two service providers working across counties, these service providers are Zain which is circles and Via (STC) which is triangulated. Generally speaking the companies working across countries adopted different patterns. Zain which is working across five countries adopted agile and product oriented patterns. Agile was adopted in two countries KSA and Iraq, however, productoriented was adopted in three countries Bahrain, Kuwait, and Jordan. Another service provider working across countries which is Viva or STC. This service provider adopted agile, and lean- oriented. Agile was adopted in Kuwait, and lean was adopted in KSA and Bahrain. So generally speaking the four hypothesis (H4) is accepted

Table 7 Scheffe Post hoc test results for the differences between strategic groups

\begin{tabular}{|c|c|c|c|c|c|}
\hline \multirow[t]{2}{*}{ Strategic Group } & \multirow[t]{2}{*}{$\begin{array}{l}\text { Relative Market } \\
\text { share realized }\end{array}$} & Agile (J) & Lean (J) & $\begin{array}{l}\text { Product oriented } \\
\text { (J) }\end{array}$ & Cost oriented $(\mathrm{J})$ \\
\hline & & I-J & I-J & I-J & I-J \\
\hline Agile (I) & $\begin{array}{c}74.2 \% \\
H^{(1)}\end{array}$ & & -14.80 & -18.20 & $48.60^{*}$ \\
\hline Lean (I) & $\begin{array}{c}89 \% \\
\mathrm{H} \\
\end{array}$ & 14.80 & & -3.40 & $63.40^{*}$ \\
\hline Product oriented (I) & $\begin{array}{c}92.4 \% \\
\mathrm{H} \\
\end{array}$ & 18.20 & 3.40 & & $66.80^{*}$ \\
\hline Cost oriented (I) & $\begin{array}{c}25.6 \% \\
\mathrm{~L} \\
\end{array}$ & $-48.60^{*}$ & $-63.40^{*}$ & $-66.80^{*}$ & \\
\hline
\end{tabular}

*p-value $<0.05$

(1) $0-<0.3: \mathrm{L},>0.3-<0.7: \mathrm{M}, 0.7-1.00: \mathrm{H}$ 
Table 8 Clusters membership for the taxonomies of mobile phone service providers' operations strategy adopted by companies of each Arab country

\begin{tabular}{|c|c|c|c|c|}
\hline Country & Agile strategic group & Lean strategic group & $\begin{array}{l}\text { Product oriented strategic } \\
\text { group }\end{array}$ & Cost oriented strategic group \\
\hline UAE & $\mathrm{Du}$ & Etisalat & & \\
\hline man & Omantel & & & $\begin{array}{c}\text { Nawras } \\
\text { Friends } \\
\text { Renna }\end{array}$ \\
\hline Qatar & Ooredoo & & & Vodafone \\
\hline Yemen & Sabafon & $\begin{array}{c}\text { Spacetel } \\
\text { Yemen mobile }\end{array}$ & & \\
\hline Lebanon & Touch & Alpha & & \\
\hline KSA & & & Mobily & \\
\hline \multicolumn{5}{|l|}{ Bahrain } \\
\hline Iraq & & Asiacell & & Korek \\
\hline Kuwait & Wataniya & & & \\
\hline Jordan & Umniah & & & \\
\hline & & & Orange & \\
\hline
\end{tabular}

$\triangle \bigcirc$ Same service provider

\section{DISCUSSION}

The number of taxonomies generated by this study is four, which is the same number of clusters generated by Kathuria (2000), Menor et al. (2001) and Zhao et al. (2006) studies. The agile strategic group is the same as mass server of Zhao et al. (2006), do all of Kathuria (2000), and agile of Menor et al. (2001). Lean taxonomy is the same as speed conformers of Kathuria (2000) and specialized contractors of Zhao et al. (2006). Product-oriented taxonomy is the same as traditional group of Menor et al. (2001), customer oriented of Aranda (2002) differentiators of Sum et al (2004) and quality customization of Zhao et al. (2006).

Agile taxonomy was the widely adopted by service providers in the Middle East region across countries, so the service providers in the Middle East region should concern about providing full package for their customers as a result of intensive competition in the region which is reflected in the high penetration rate.

The close patterns in term of relative market share are agile, lean and product oriented, these three patterns are significantly better than the cost-oriented. The cost is no longer the most effective strategic pattern since the service providers are very close in the cost. Further, the mobile phone services in the Middle East are well developed and customers in the region are well experienced, so they are looking for more than the cost. The cost-oriented strategy is more effective at the launching stage of mobile phone service in a particular country.

The most effective pattern was product-oriented. During the last years the customers in the Middle East ask for $3 \mathrm{G}$ services. So the packages of services extended to include more services. Product-oriented was adopted by five countries (KSA, Bahrain, Kuwait, Jordan), the service in these countries was earlier launched in comparison with other countries. Cost-oriented was adopted by three countries (Iraq, Qatar and Oman), the service in Iraq was recently launched, the three service providers adopted this pattern in Oman are virtual operators.

The same service providers which provided service across countries adopted different patterns. The patterns adopted by these companies were effective; this indicates that; the companies working across countries are mature enough to adopt the effective patterns.

Three of taxonomies out of four adopted by mobile phone service providers were effective. However the results of previous studies as Miller and Roth (1994); Kathuria (2000) Menor et. (2001); and Sum et al. (2004) shows more differences between taxonomies in term of performance. This could be related to the differences in sectors. The previous studies have mainly reported the manufacturing sector's taxonomies. Further, the previous studies have 
reported different financial and financial indicators so more differences have been identified.

The effective taxonomies reported by this study were the same as reported by the previous studies. The agile strategic group was reported as an effective taxonomy by Menor et al. (2001) and do all taxonomy which is close to agile was reported as an effective taxonomy by Kathuria (2000). Also lean strategic group or what is called by Kathuria (2000) as speedy performers was an effective taxonomy. Product oriented taxonomy or what is called by Sum et al. (2004) as a differentiator and what is called as a marketer by Miller and Roth (1994) were effective taxonomies. This indicates there are shared effective taxonomies across industries.

\section{CONCLUSION, APPLICATIONS AND FUTURE RESEARCHES}

\subsection{Contribution and Results}

The taxonomies of operations strategy is an extension of operations strategy contribution which has been a research issue since the mid 1990s, reporting taxonomies is a part of research stream of operations strategy configuration. The taxonomies have been reported in one country context and for manufacturing sector. Accordingly, in this study the taxonomies of mobile phone service providers across Arab countries of the Middle East region were reported.

The taxonomies adopted by mobile service providers in the Arab Middle East were agile, lean, product-oriented and cost-oriented. The widely adopted taxonomy across countries was agile. The least effective taxonomy was costoriented. Agile, lean and cost oriented were very close in the relative market share. The service providers working across countries in the region as Zain and STC adopted different taxonomies, and the taxonomies adopted were the most effective, and each service provider in each country adopted unique taxonomy in comparison with the competitors of the same country.

\subsection{Applications and Future Researches}

The operations managers of mobile phone service providers in each country in the Middle East region has a better insight about the effective strategic patterns to sustain or adopt in the future. Further the new potential competitors have an insight about the effective patterns to adopt.

This research shed the light on the taxonomies of operations strategy across countries in one region, the future research can be extended to make comparison across regions. This study is a snap shot study, it is recommended for future researches to adopt time series studies in order to report the emergent and sustained taxonomies. The effectiveness of taxonomies was evaluated by the relative market share indicator, other indicators as financial performance, customer satisfaction and retention could be investigated.

\section{REFERENCES}

Aranda, D. (2003). Service operations strategy, flexibility and performance in engineering consulting firms. International
Journal of Operations \& Production Management 23(11), pp. 1401-1421.

Bozarth, C., \& McDermott, C. (1998). Configurations in manufacturing strategy: a review and directions for future research. Journal of Operations Management 16(4), pp. 427-439.

Curwen, P., \& Whalley, J. (2007). Tele2 and the strategic role of virtual operations. info 9(4), pp. 55-69.

Dahlström, P. W., Deprez, F., \& Steil, O. (2004). Meeting the nofrills mobile challenge. Mckinsey Quarterly, pp. 9-11.

Doty, D. H., \& Glick, W. H. (1994). Typologies as a unique form of theory building: Toward improved understanding and modelling. Academy of management review 19(2), pp. 230251.

Fjeldstad, Ø. D., Becerra, M., \& Narayanan, S. (2004). Strategic action in network industries: an empirical analysis of the European mobile phone industry. Scandinavian Journal of Management 20(1), pp. 173-196.

Frohlich, M. T., \& Dixon, J. R. (2001). A taxonomy of manufacturing strategies revisited. Journal of Operations Management 19(5), pp. 541-558.

Fuentelsaz, L., Maícas, J. P., \& Polo, Y. (2008). The evolution of mobile communications in Europe: The transition from the second to the third generation. Telecommunications Policy 32(6), pp. 436-449.

Hill, T., \& Hill, A. (2009). Manufacturing strategy: text and cases. Palgrave Macmillan.

International Telecommunication Union (2010) The World in 2010: Facts and Figures, International Telecommunication Union, Geneva, Switzerland.

International Telecommunication Union (2014) The World in 2014 ICT: Facts and Figures, International Telecommunication Union, Switzerland, Geneva.

Filiz Karabag, S., \& Berggren, C. (2011). Mobile communications in Turkey: from first mover advantages to management capabilities. info 13(2), pp. 72-84.

Kathuria, R. (2000). Competitive priorities and managerial performance: a taxonomy of small manufacturers. Journal of Operations Management 18(6), pp. 627-641.

Kellogg, D. L., \& Nie, W. (1995). A framework for strategic service management. Journal of Operations Management 13(4), pp. 323-337.

Lowson, R. H. (2003). Strategic operations management: the new competitive advantage. Routledge.

Lowson, R. H. (2003). How supply network operations strategies evolve: composition, competitive priorities and customisation. International Journal of Physical Distribution \& Logistics Management 33(1), pp. 75-91.

Markova, M., Aula, A., Lonnqvist, A., \& Wigelius, H. (2008). Identifying and measuring the success factors of mobile business services. International Journal of Knowledge Management Studies 2(1), pp. 59-73.

Luz Martín-Peña, M., \& Díaz-Garrido, E. (2008). Typologies and taxonomies of operations strategy: a literature review. Management Research News 31(3), pp. 200-218.

Meyer, A. D., Tsui, A. S., \& Hinings, C. R. (1993). Configurational approaches to organizational analysis. Academy of Management journal 36(6), pp. 1175-1195.

Menor, L. J., Roth, A. V., \& Mason, C. H. (2001). Agility in retail banking: A numerical taxonomy of strategic service groups. Manufacturing \& Service Operations Management 3(4), pp. 273-292.

Metters, R., \& Vargas, V. (2000). A typology of de-coupling strategies in mixed services. Journal of Operations Management 18(6), pp. 663-682.

Migdadi, Y. K. A. A. (2012). The order winners' operations strategy of mobile phone service providers in developing economies: the case of Jordan. International Journal of Services and Operations Management 13(3), pp. 329-360. 
Migdadi, Y. K. A. A. (2013). Proposed typologies of banking operations strategy. International Journal of Services and Operations Management 16(1), pp. 42-85.

Migdadi, Y.K.A.A., (2014). Identifying the best practices in banking operations strategy in developing economics: the case of Jordan. International Journal of Business Excellence 8(1), pp. 38-84.

Miles, R. E., Snow, C. C., Meyer, A. D., \& Coleman, H. J. (1978). Organizational strategy, structure, and process. Academy of management review 3(3), pp. 546-562.

Miller, D. (1996). Configurations revisited. Strategic management journal 17(7), pp. 505-512.

Miller, J. G., \& Roth, A. V. (1994). A taxonomy of manufacturing strategies. Management Science 40(3), pp. 285-304.

Mintzberg, H., \& Waters, J. A. (1985). Of strategies, deliberate and emergent. Strategic management journal 6(3), pp. 257272.
Sum, C. C., Shih-Ju Kow, L., \& Chen, C. S. (2004). A taxonomy of operations strategies of high performing small and medium enterprises in Singapore. International Journal of Operations \& Production Management 24(3), pp. 321-345.

UNDP (2010) 2010 Statistical Update: Jordan, the Human Development Index-Going beyond Income. Accessed February 20, 2011 http://www.hdrstats.undp.org/en/statistics

Valletti, T. M. (1999). A model of competition in mobile communications. Information Economics and Policy 11(1), pp. 61-72.

Zhao, X., Sum, C. C., Qi, Y., Zhang, H., \& Lee, T. S. (2006). A taxonomy of manufacturing strategies in China. Journal of Operations Management 24(5), pp. 621-636.

Zhang, D. Z. (2011). Towards theory building in agile manufacturing strategies-Case studies of an agility taxonomy. International Journal of Production Economics 131(1), pp. 303-312.

Dr. Yazan Khalid Abed-Allah Migdadi is an Associate professor of operations management at business department, Yarmouk University, Jordan. He was awarded Ph.D. in operations management from Bradford University, UK, also awarded BA and MBA from Yarmouk University, Jordan. He worked as a teaching assistant and a researcher of operations and information management at Bradford University, School of Management, UK. His main research interest is reporting operations strategy: best practices, taxonomies, process, and typologies. 